\title{
Fracture Toughness Evaluation of AA3003 Aluminum Alloy through Alternative Experimental Methods and Finite Element Technique
}

\author{
M. JOEMAX AGU*, T. CHRISTOPHER** \\ *Faculty of Mechanical Engineering, C.S.I. Institute of Technology, Thovalai-629 302, India, \\ E-mail: joemaxagu@gmail.com. \\ **Faculty of Mechanical Engineering, Kamaraj College of Engineering and Technology, Madurai District-625701, India, \\ E-mail:tchristo59@gmail.com.
}

cross $^{\text {ref }}$ http://dx.doi.org/10.5755/j01.mech.24.5.21173

\section{Introduction}

The structural integrity assessment of a material in the presence of preexisting flaw or an assumed defect falls under purview of fracture mechanics. Though more parameters used for quantifying the effect of crack in structural component plane strain fracture toughness is the frequently used one. Conventional fracture toughness testing involves higher material and facility cost. Hence there is an interest among researchers to look for alternate test methods including non destructive technique. Ball indentation test is one among them

Has conducted ball indentation test to study the elastic/plastic deformation behavior of aluminum 2024 [1]. The elastic modulus of the material has been predicted by measuring the peak load (plastic) and depth and correlating with empirical relations. Evaluated fracture toughness from Vickers indentation and tensile data [2]. A theoretical model of for Indentation Energy to Fracture (IEF) was developed and $K_{I C}$ values were compared with CVN energy data. Predicted energy parameter correlation of failure life data between cyclic ball indentation and low cycle fatigue [3]. Finite element simulation of ball indentation was successfully done and the region of failure was determined with appropriate empirical relations. Determined yield strength by developing stress-strain micro probe setup in which the diameter of the grain size is also included in the empirical relation to identify the fracture toughness $[4,5]$. The test is best suited for metallic materials for thin applications. Conducted spherical indentation test on metallic materials and compared stress-strain curve values with an optimization algorithm [6]. Material uni-axial properties were analyzed with $\sigma-\varepsilon$ curves. The results were also compared with Hertzian analytical solution for elastic contact. Derived equations for non-linear bending of cantilever and 3-point bending of beams which obeys the Ramberg-Osgood behavior [7]. Standard mathematical relations were adopted to analyze the bending moment and bending stress and the same is correlated to toughness of the material. Developed relation between stress intensity factor and crack indent size to achieve fracture toughness according to Lankford formula [8]. For validation the results have been compared with direct crack measurement. The test results showed better agreement for specimens that produce radial pattern when indented. Assessed the fracture toughness of aluminum by punch test and validated through FEA [9]. The strain energy density and plastic energy were studied from specific models. The test was mainly adopted to study the ductile-brittle transition of aluminum 6061. The results showed an increase of fracture toughness and aging (temperature) of the specimen. Evaluated fracture toughness by miniaturized 3 point bend specimen ranges from 3.3 to $7.0 \mathrm{~mm}$ thickness [10]. The test was conducted under Mode-I loading conditions. The fracture toughness values were obtained using loaddeformation curve. In this method AA3003 material is selected as it has high ductility and corrosion resistance also this specific aluminum alloy is used for designing pressure vessels for its desired strength. Ball indentation test has been adopted with steel indenter made of chromium and also three point bend test to calculate $K_{I C}$ of the material.

From the literature review it concludes that Ball Indentation test provides methodology for calculation of plane strain facture toughness which is essentially meant for conservative design of thick components. In thick applications light weight requirement is not insisted and also the test method is also simple and less costly. The present work primarily aims at determination of fracture toughness from cyclic ball indentation test and the non-linearity of the material is validated through FEA. Three point bend test is also conducted under room temperature for the conformity of toughness value from ASTME1290-08 and simulated for better results. With not much of researches in this area it motivates to study the material behavior during indentation and its relevance to fracture toughness. Hence it is the interest of this research to simulate the process as closely as possible and validate through simple testing methods including ball indentation test, and three point bend test. The peak load obtained from both the test was determined as the failure load and fracture toughness value was calculated using the empirical relations.

\section{Ball Indentation Test on AA3003 Plate}

AA3003 material has been chosen as an easily available material which is used for manufacture of low strength pressure vessels and tanks. This is non corrosive and highly ductile. The geometry of the specimen is $120 \mathrm{x}$ $30 \mathrm{~mm}$ and thickness $4 \mathrm{~mm}$. AA3003 plate was indented with a chromium steel ball of $4 \mathrm{~mm}$ diameter. A universal testing machine with 3 metric ton capacity servo controlled has been utilized for indentation purpose. A specially designed holder was made of SS310 steel to hold the ball on to the ram of the machine as shown in Fig. 1. 


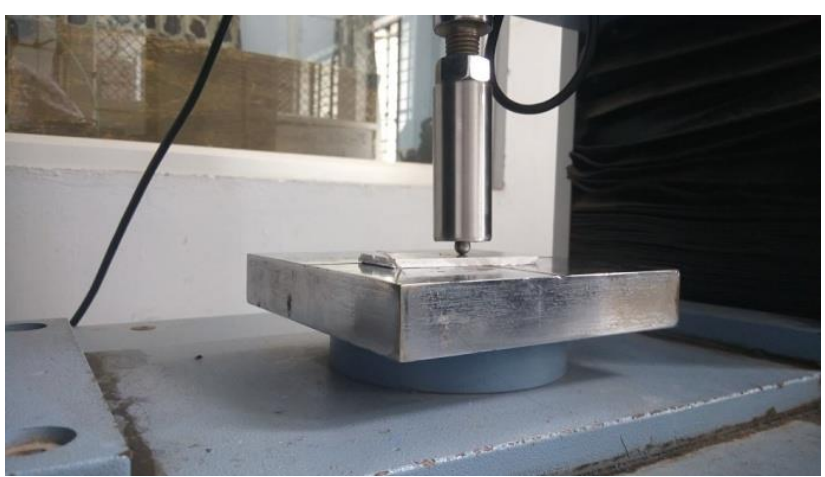

Fig. 1 AA3003 loaded over a base plate with a specially designed holder for indentation

Loading was done under minimum strain rate of $0.1 \mathrm{~mm} / \mathrm{min}$ for better accuracy for the load - depth values. The radius of indentation for the corresponding load was also calculated by using empirical relation given in Eq. (1).

$$
a=\sqrt{2 R h-h^{2}},
$$

where $a$ is the radius of indentation, $R$ is radius of indenter and $h$ is the penetration depth.

Material properties of specimen and indenter

\begin{tabular}{|c|c|c|}
\hline Properties & Specimen: AA3003 & $\begin{array}{l}\text { Indenter: Chro- } \\
\text { mium steel }\end{array}$ \\
\hline $\begin{array}{l}\text { Young's } \\
\text { Modulus }\end{array}$ & $70 \mathrm{GPa}$ & $279 \mathrm{GPa}$ \\
\hline $\begin{array}{l}\text { Poisson's } \\
\text { ratio }\end{array}$ & 0.29 & 0.21 \\
\hline $\begin{array}{l}\text { Yield } \\
\text { Strength }\end{array}$ & $145 \mathrm{MPa}$ & - \\
\hline $\begin{array}{l}\text { Ultimate } \\
\text { Strength }\end{array}$ & $165 \mathrm{MPa}$ & - \\
\hline Size & Thickness $4 \mathrm{~mm}$ & $4 \mathrm{~mm}$ Dia \\
\hline
\end{tabular}

Table 2

Experimental value of load and depth of indentation AA3003 aluminum alloy

\begin{tabular}{|l|c|c|}
\hline Load, N & Depth $h, \mathrm{~mm}$ & Radius $a, \mathrm{~mm}$ \\
\hline 0 & 0 & 0.00 \\
823.3533 & 0.19 & 0.85 \\
1647.688 & 0.53 & 1.36 \\
2469.177 & 0.64 & 1.47 \\
3293.217 & 0.74 & 1.55 \\
4118.238 & 0.85 & 1.64 \\
4939.335 & 0.94 & 1.70 \\
5763.375 & 0.99 & 1.73 \\
6586.434 & 1.17 & 1.82 \\
7528.194 & 1.42 & 1.91 \\
\hline
\end{tabular}

The following Table 1 describes about the material properties of selected specimen and indenter. Continuous indentation was done on the AA3003 specimen by loading even beyond the yield strength. Force displacement curves were obtained from the experiment and were also used to estimate the yield strength of the material from equations provided by [5]. The load and displacement values obtained from the experiment are given in Table 2.

From Haggag's theory the fracture toughness was determined by Eq. (2):

$$
K_{I C}=\kappa \sqrt{n l_{0}^{*} E \sigma_{y s}},
$$

where $K_{I C}$ is plane strain fracture toughness, $n$ is strain hardening exponent obtained from graph $\left(P / d_{t}^{2}\right)$ and $\left(d_{t} / D\right)$, $l_{0}^{*}$ is the characteristic distance ahead of the crack, $E$ is the youngs modulus of the material and $\sigma_{y s}$ is the yield strength of the material, $\kappa$ is the geometrical constant and the value is 3 .

Fig. 2, shows the graph from which value of $n$ is determined from the trend line plotted with equation in linear form. On substituting the values in Eq. (2) the plain strain fracture toughness obtained is $136.27 \mathrm{MPa} \vee \mathrm{m}$. The yield stress obtained from this procedure is $144.86 \mathrm{MPa}$.

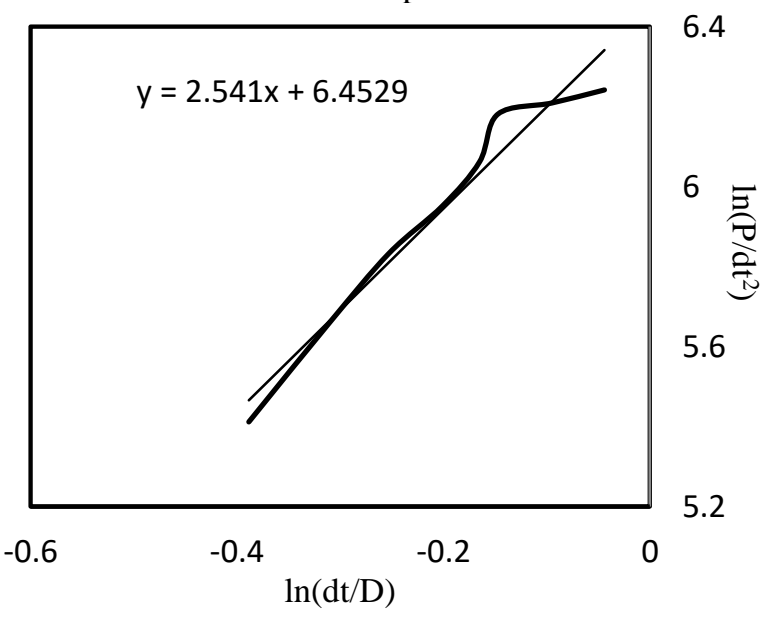

Fig. 2 Plot to determine strain hardening exponent

\section{Finite Element Analysis of Ball Indentation Test for AA3003}

For solving structural problems FEA tool Ansys is commonly used. Ansys software has the capability for analyzing the elastic and elastic-plastic conditions. Extensive researches have been taking place for revising the element types and to simulate the behavior of the material with geometrical intricacies including the boundary conditions. In this work, an attempt is made to simulate ball indentation process by performing contact analysis between the indenter and specimen. For this purpose of simulation elastic-plastic material behavior, a smooth stressstrain curve was generated using Ramberg- Osgood relation given by [7].

$$
\sigma=E \varepsilon\left\{1+\left(\frac{\varepsilon}{\varepsilon_{0}}\right)^{n}\right\}^{-\frac{1}{n_{0}}},
$$

where $\varepsilon_{0}$ and $n_{0}$ are material constants obtained by fitting to the actual uniaxial tensile test data. The values for these constants are given as $\varepsilon_{0}=0.002357$ and $n_{0}=4.8$.

The material model above gives stress values only with positive slope and it reaches ultimate tensile strength asymptotically according to its design. The stress-strain 
values generated by the curve were suitable for understanding the material failure under loading conditions. The smooth curve for the analysis was shown in Fig. 3, and the values are given as input for simulation.

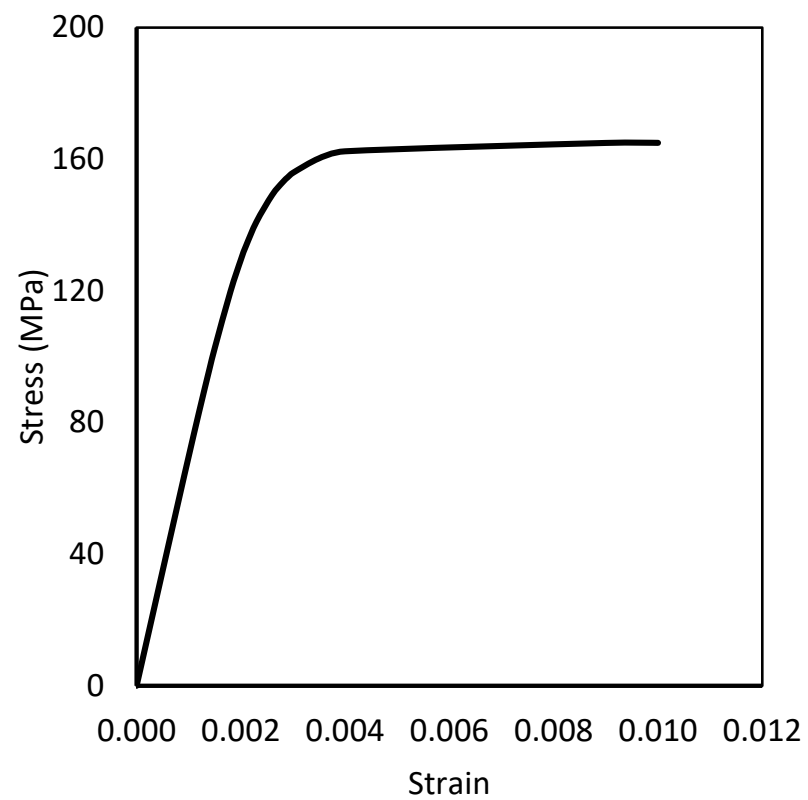

Fig. 3 Material stress strain data

For creating the model of the specimen, 8 noded quadrilateral elements plane 183 has been utilized with axi-symmetric option. The axi-symmetric model of the geometry is shown in Fig. 4. Convergence study has been made with more elements and the final model consists of 258 elements and 766 nodes.

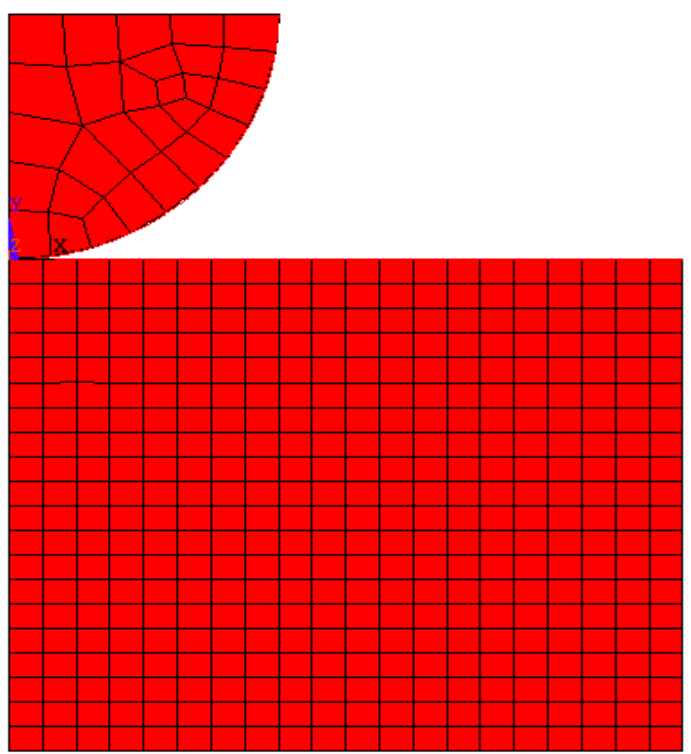

Fig. 4 Finite element model of the specimen and indenter in contact

The mesh elements were refined considering the geometrical conditions and the displacement corresponding to radius was obtained with relative error of $0.1 \%$ when compared to the experimental results. Fig. 5, shows a comparison of depth vs radius of the indenter obtained through experiment and finite element analysis.

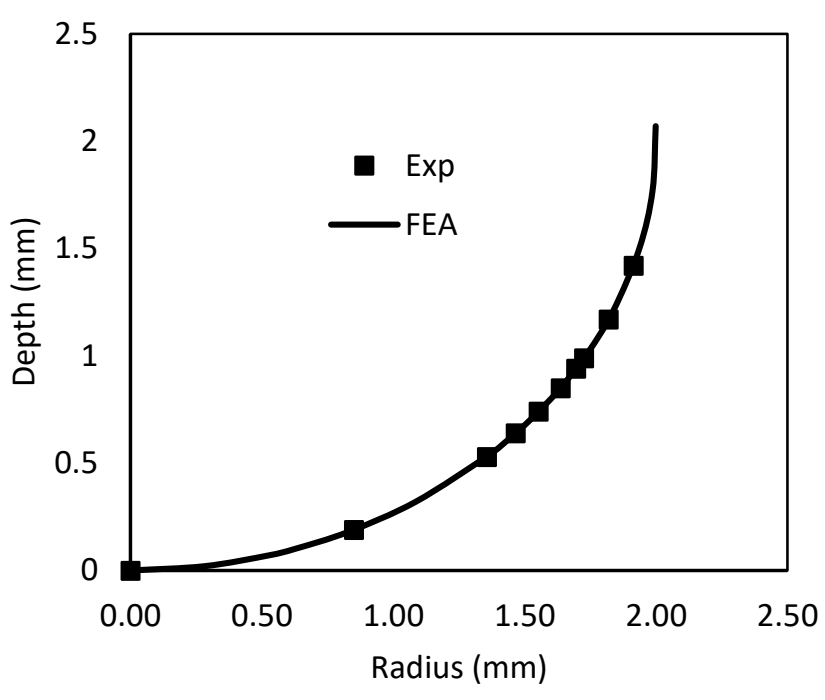

Fig. 5 Depth Vs Radius of the indenter for continuous loading

The contact area was created between the surface of the specimen and indenter as shown in Fig. 6. The contact between the plate and indenter is defined by contact and target elements (CONTA 171, and TARGE 169) of Ansys. The remaining areas are kept under free mesh.

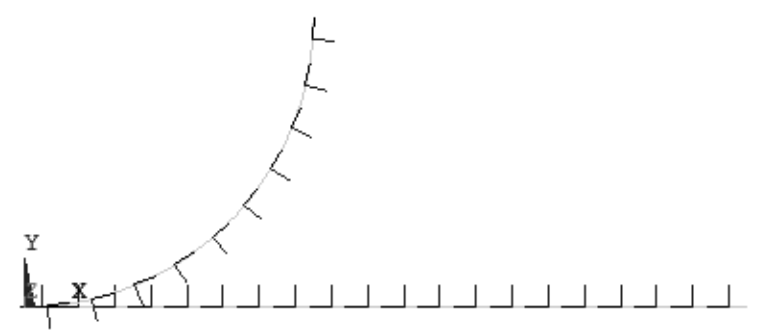

Fig. 6 Contact area between indenter and specimen

Predicted from the load-depth curve that the non linear reduction in the applied load was due to the depth of indentation and spherical geometry of the indenter [11]. Due to continuous loading the plastic deformations of the metal increases and hence strain hardening was developed. In ball indentation technique, initially the ball has a point contact and the singularity so produced is similar to that produced at the crack tip of fracture testing specimens. Here, there is no physical crack. However, as the load increases a plastic zone is developed around the point of contact which is also a common occurrence with fracture testing specimen. Hence researches have started correlating the energy to fracture in case of two phenomena and hence to determine the mechanical flow properties and critical stress intensity factor

Load-depth curve is also generated by finite element analysis and is shown in Fig. 7, and is validated from FEA technique.

The strain hardening is obtained from the true stress strain data of the material. The indentation profile was studied by the material pile up occurring during loading of the specimen. The crater shape observed is as predicted by [6]. The material pile up is evident both in Figs. 8 and 9. 


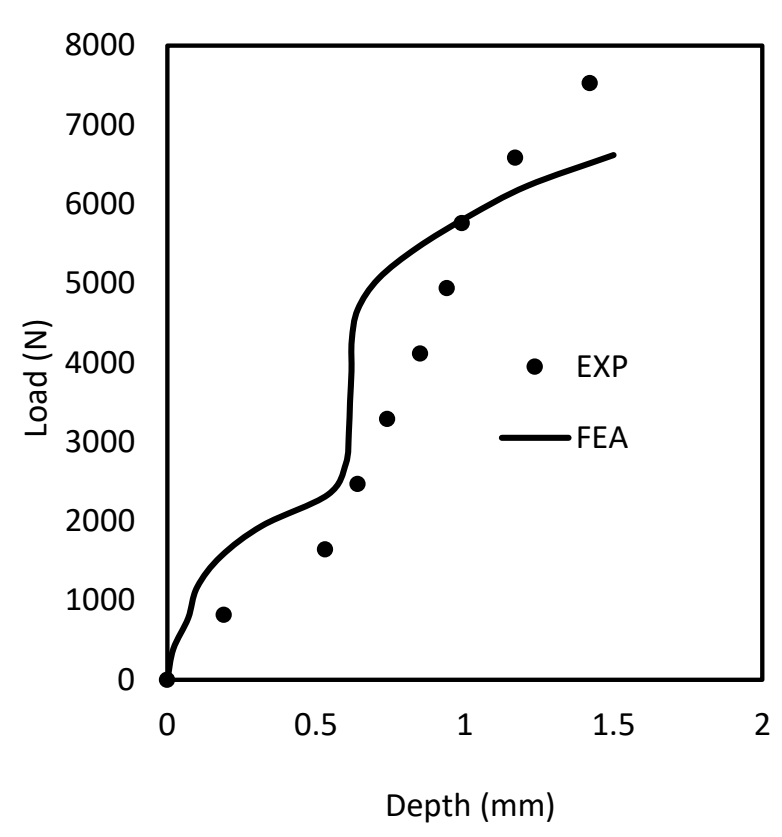

Fig. 7 Comparison of results of experiment and finite element analysis of AA3003 Aluminum alloy

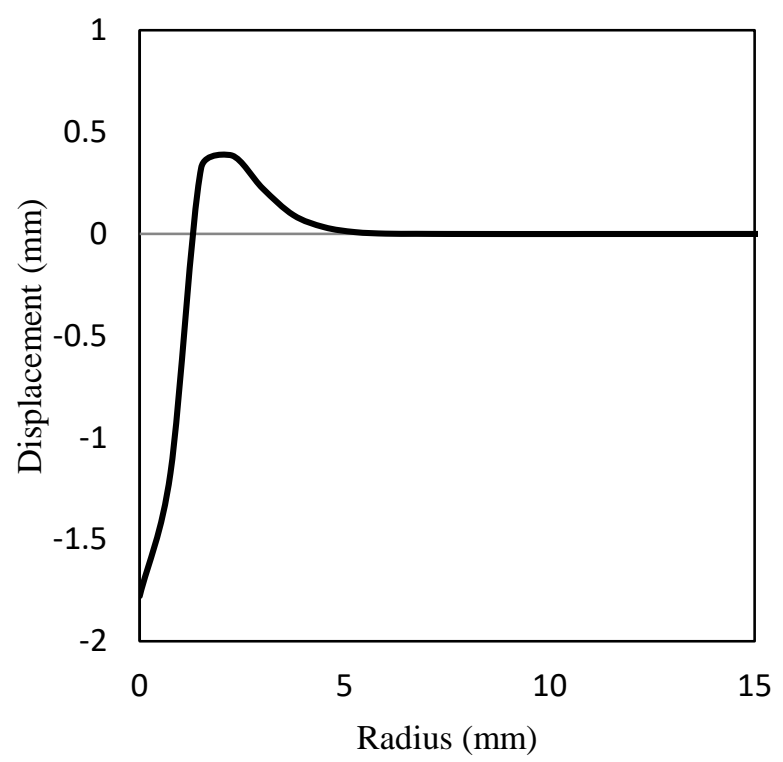

Fig. 8 Penetration depth Vs radius as recorded from finite element analysis

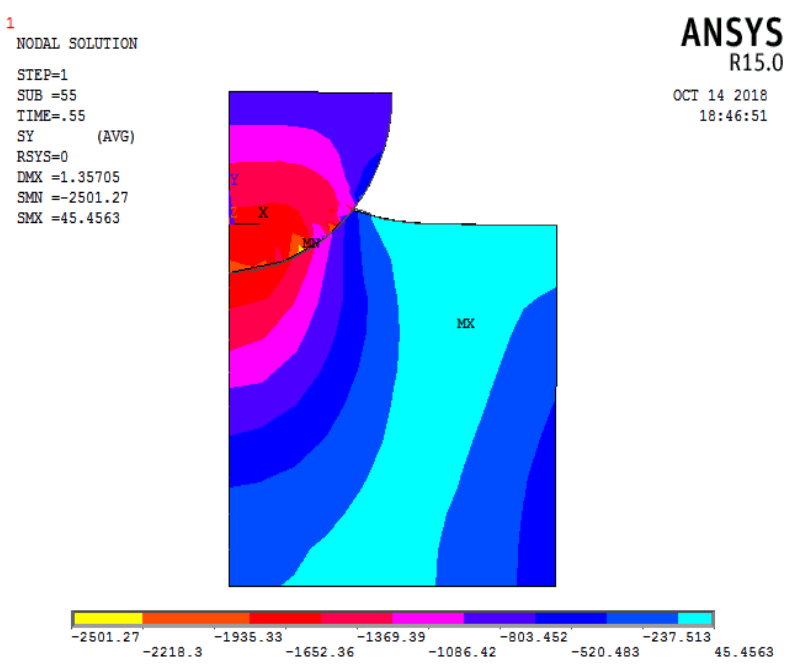

Fig. 9 Material pileup for maximum load
The effective stress produced in the specimen gradually decreases from the centre of the indenter and approaches to zero at a distance away from it. It is true with all load steps. The effective stress vs radius is plotted for different loads and shown in Fig. 10.

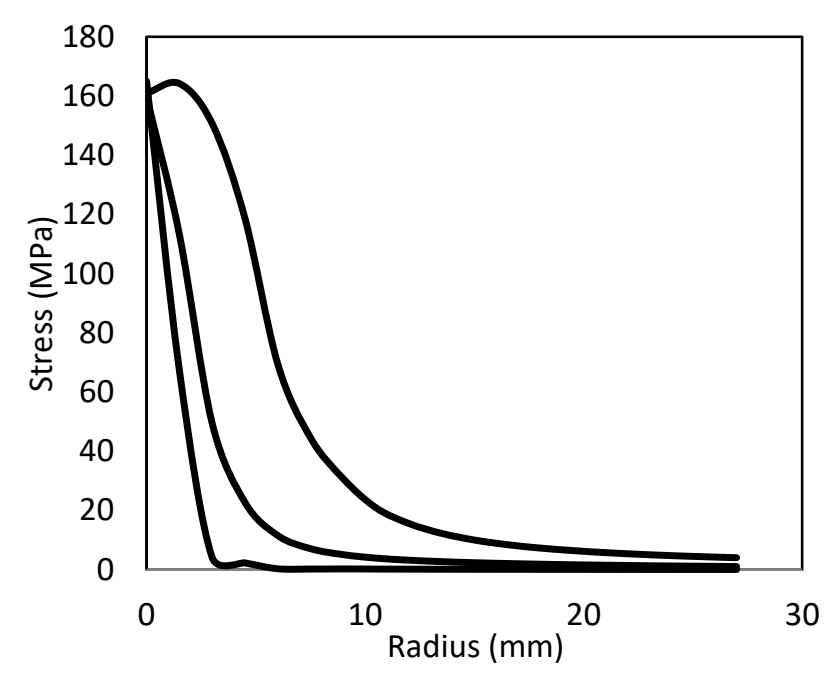

Fig. 10 Stress vs radius of impression

The progression of the analysis utilizes the time steps of the stress-strain curve obtained from Ramberg Osgood relation. The program terminates when very large deformation occurs. This state denotes the critical load which might be of some use in determining the plane strain fracture toughness. In their paper proposed a method for the determination of yield stress and fracture toughness by using regression analysis from the data obtained [4]:

$$
\sigma_{y s}=\beta_{m} A,
$$

where $A$ is to be determined by fitting Load vs Depth of penetration (Fig. 2) to the equation:

$$
\frac{P}{d_{t}^{2}}=A\left(\frac{d_{t}}{D}\right)^{m-2}
$$

where $P$ is load, $d_{t}$ is depth of penetration, $d$ is indentation diameter and $D$ is diameter of indenter.

Taking logarithms on both sides:

$$
\ln \left(\frac{P}{d_{t}^{2}}\right)=(m-2) \ln \left(\frac{d_{t}}{D}\right)+\ln (A)
$$

a plot is drawn between $\ln \left(\frac{P}{d_{t}^{2}}\right)$ and $\ln \left(\frac{d_{t}}{D}\right) y$ intercept will be the value of $\ln (A)$. The value of $A$ is the exponent obtained from the curve shown in Fig. 11.

The value of $A$ obtained is exponent of the intercept 6.472 is obtained as 646.776. The $\beta$ is value prescribed is a material type constant 0.2 is 285 which is applicable to all materials which have considerably low strength. Hence using equation (4), the yield stress is obtained as $147.78 \mathrm{MPa}$.

The value is very close to experimental observation and showed $2 \%$ error which is acceptable. The strain 
hardening exponent ' $n$ ' for the Eq. (2) was also calculated according to ASTM E-646-78. The slope of the true stress/true strain value is plotted by using log scale and the value is 2.243 . On substituting the values in Eq. (2) the fracture toughness obtained is $128.03 \mathrm{MPa} \sqrt{\mathrm{m}}$. It is very close to the experimental result 136.27 $\mathrm{MPa} \vee \mathrm{m}$.

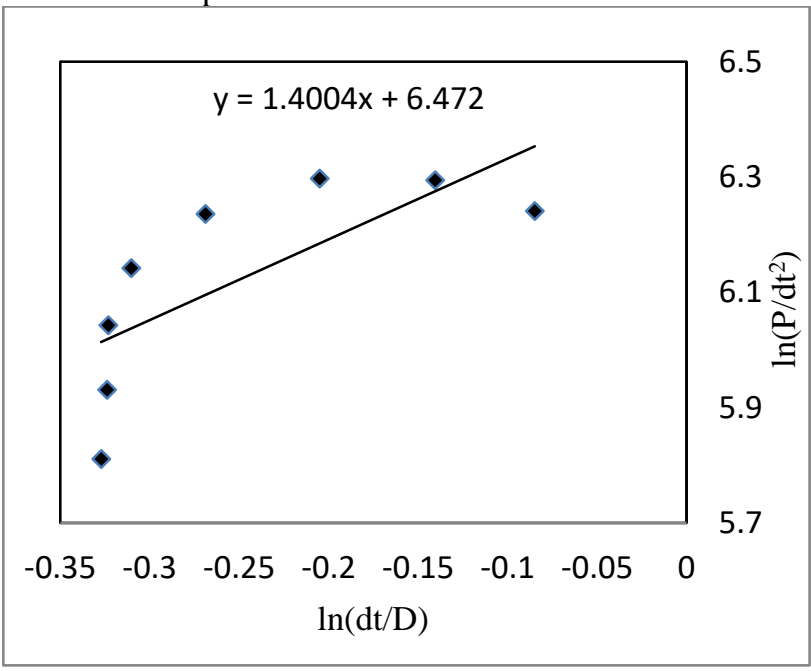

Fig. 11 Evaluation of parameter A from indentation test

The observed fracture toughness values were also compared with 3 point bend test by ASTM E1290-08. In both the methods loading rate was maintained constant

\section{Three Point Flexural Test}

It is one of the small specimen test for evaluating fracture toughness. The specimen was prepared according to ASTM D790-17 standard. From the three point bend test the peak load was determined and the same is used to find fracture toughness. On considering the practical importance it is negligible. The geometry of the specimen is given in Fig. 12. The specimen is prepared according to ASTM standards with the geometry of $120 \mathrm{~mm}$ length, $30 \mathrm{~mm}$ width and $4 \mathrm{~mm}$ thickness. A Specially designed plunger made of SS310 steel was utilized to apply load gradually behind the notch. SS310 steel was selected due to its high strength.
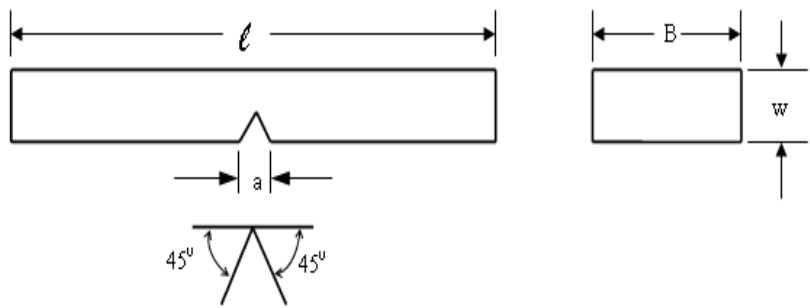

Fig. 12 Geometry of the specimen for three point bend test

The ease of specimen preparation in flexural test is more advantage. The results obtained from testing method are sensitive when compared to the strain rate. The loading of the specimen is shown in Fig. 13.

The obtained fracture toughness by this test method is a function of $a$ and $w$. Various measurements of linear dimensions of the specimen and considering the design of the fixtures the load displacement record was made as shown in Fig. 14.

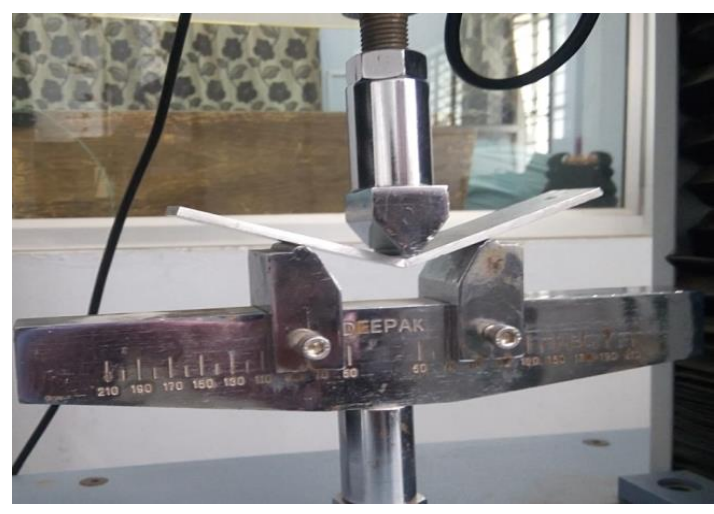

Fig. 13 Specimen loaded for three point bend test

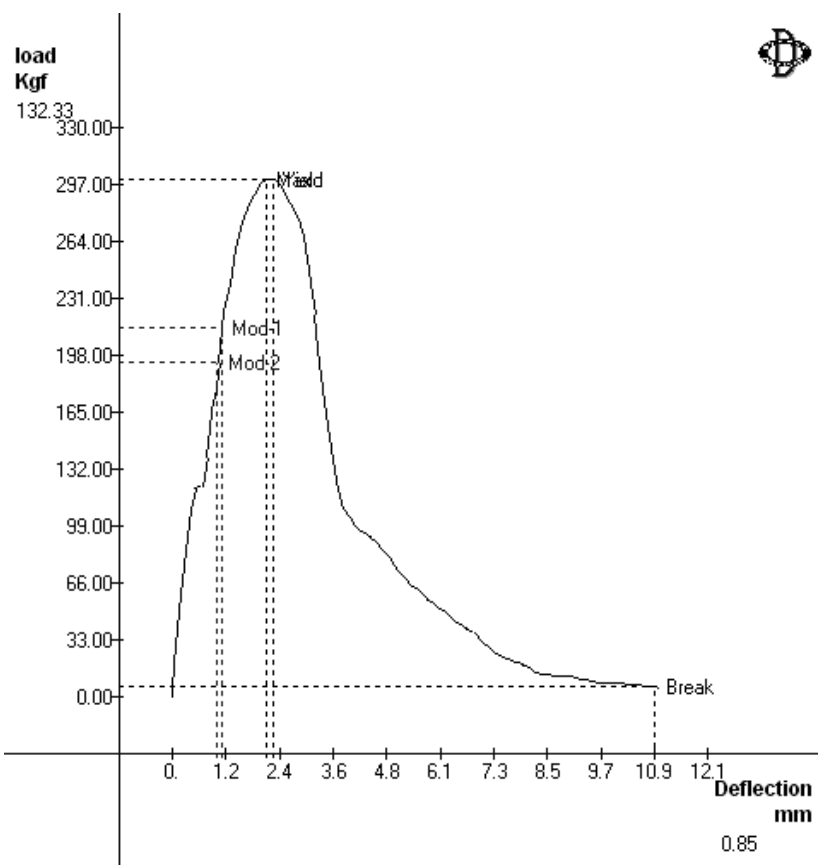

Fig. 14 Load - Deformation curve recorded from loading with $0.1 \mathrm{~mm} / \mathrm{min}$ strain rate

The specimen was pre-cracked with a notch of length of $1 \mathrm{~mm}$ and with an extruded angle of $45^{\circ}$. The loading of the specimen was done on the same UTM machine with specially designed fixtures. The maximum peak load assessed from the experiment was $3015 \mathrm{~N}$ and the plane strain fracture toughness was obtained by using following Eq. (7):

$$
K_{I C}=\frac{6 P}{B W} a^{\frac{1}{2}} y \operatorname{MPa} \sqrt{m},
$$

where $P$ is the peak load attained at the time of breakage, $B$ is the width of the specimen, $W$ is the thickness of the specimen, $a$ is the crack length which is equal to $1 \mathrm{~mm}$ and $y$ is the function of $(a / w)$ which is given in Eq. (8):

$$
y=\frac{1.99-\frac{a}{w}\left(1-\frac{a}{w}\right)\left(2.15-3.93 \frac{a}{w}+2.7\left(\frac{a}{w}\right)^{2}\right)}{\left(1+2 \frac{a}{w}\right)\left(1-\frac{a}{w}\right)^{\frac{3}{2}}}
$$


On substituting the values in the above equations (7) and (8) the $K_{I C}$ value obtained was $134.469 \mathrm{MPa} \sqrt{\mathrm{m}}_{\mathrm{m}}$ which were interestingly close to the value obtained from ball indentation test.

\section{Finite Element Simulation of Three Point Flexural Test}

The beam was modeled in using ANSYS software by selecting plane 183 elements. Plane strain method was opted for the analysis. A smooth stress-strain curve was generated using equation (3) to perform nonlinear analysis. The constrained model was generated and the boundary conditions were applied as shown in Fig. 15. The meshed model of the problem contains 1229 elements and 4080 nodes shown in Fig. 16.

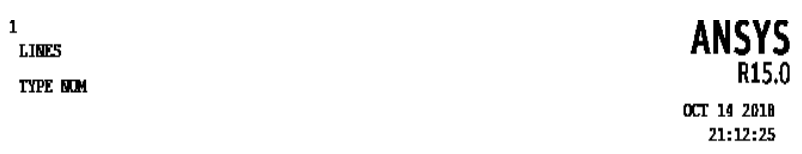

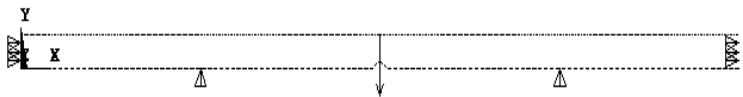

Fig. 15 Constrained position modeled for three point bend test

ANSYS

R15.0
ELEVENTS
OCT 142018
$21: 18: 48$

Y

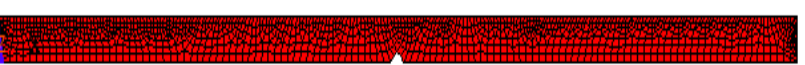

Fig. 16 Meshed model for 3 point bend test

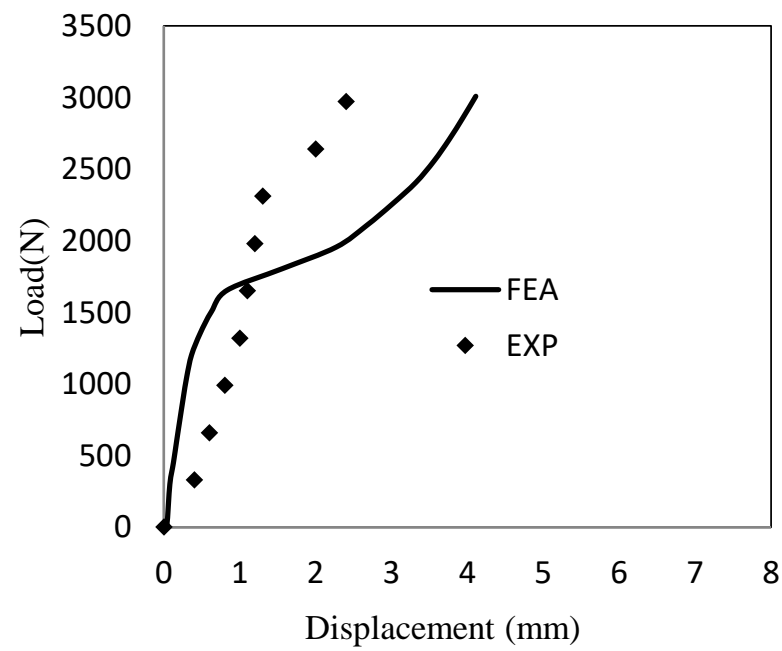

Fig. 17 Load - Deformation record from flexural test

The maximum deformation attained while applying the load is $4.11 \mathrm{~mm}$. The load deformation curve was also recorded for each load steps and the peak load was observed. The failure load obtained from the FEA model is $3008 \mathrm{~N}$. The load deformation curve is shown in Fig. 17. This is comparable with Fig. 14.
The Plane strain fracture toughness value was assessed by substituting the values in Eqs. (7) and (8) and was found to be $134.15 \mathrm{MPa} \sqrt{\mathrm{m}}$ which is very close to the experiment value of $134.469 \mathrm{MPa} \sqrt{\mathrm{m}}$

\section{Results and Discussion}

This study is aimed by predicting a methodology for determining fracture toughness by using experiments and finite element analysis. Ball indentation and flexural bending test were carried out and load deformation curves were obtained. In addition to the experiments, finite element simulation was done on indentation and 3point bend test for recording the load-deformation curve. The deformation curve obtained from ball indentation reveals a very similar technique of deformation ahead of crack tip. The flow properties were also measured using BI test. Table 3 gives a clear picture of comparison of different approaches determining fracture toughness and yield strength.

Table 3

Comparison of results obtained through different methods

\begin{tabular}{|l|l|l|l|l|}
\cline { 2 - 5 } \multicolumn{1}{c|}{} & $\begin{array}{c}\text { Ball } \\
\text { indenta- } \\
\text { tion test }\end{array}$ & $\begin{array}{c}\text { FEA of } \\
\text { ball inden- } \\
\text { tation test }\end{array}$ & $\begin{array}{c}\text { 3-point } \\
\text { bend test }\end{array}$ & $\begin{array}{c}\text { FEA of } \\
\text { 3-point } \\
\text { bend } \\
\text { test }\end{array}$ \\
\hline $\begin{array}{l}\text { Fracture } \\
\text { Tough- } \\
\text { ness, } \\
\text { MPa }\end{array}$ & 136.27 & 128.03 & 134.15 & 134.469 \\
\hline $\begin{array}{l}\text { Yield } \\
\text { stress, } \\
\text { MPa }\end{array}$ & 144.86 & 147.78 & --- & --- \\
\hline
\end{tabular}

\section{Conclusion}

The material model has been handled with finite element procedure to simulate ball indentation test and 3 point bend test. Fracture toughness was evaluated from ball indentation test and flexural analysis. ASTM standard equations were used for analytical methods. The research can be further extended by eliminating the empirical value of characteristic distance ahead of the crack tip by doing micro structural analysis. The 3 point bend test can also further be extended to calculate Crack Mouth Opening Displacement (CMOD). This research can also be established with further testing with more samples and extending to other materials applicable to critical applications.

\section{References}

1. Louis Ferranti Jr.; Ronald Armstrong, W.; Naresh, Thadhani N. 2003. Elastic/plastic deformation behavior in a continuous ball indentation test, Material Science and Engineering, Elsevier science, 371: 251-255. https://doi.org/10.1016/j.msea.2003.12.003.

2. Mohammadi, A.H.; Naderi, M.; Iranmanesh, M. 2011. Fracture toughness evaluation of $3 \mathrm{Cr}-1 \mathrm{Mo}$ steel from Vickers indentation and tensile test data, ScienceDirect, Procedia Engineering, 10: 228-235. https://doi.org/10.1016/j.proeng.2011.04.041.

3. Aneesh Bangia; Raghu Prakash, V. 2012. Energy Parameter Correlation of Failure Life Data between 
Cyclic Ball Indentation and Low Cycle Fatigue, Open journal of metals, 2: 31-36. https://doi.org/10.4236/ojmetal.2012.21005.

4. Fahmy Haggag, M.; Nanstad, R.K. 1989. Estimating Fracture Toughness Using Tension or Ball Indentation Tests and a Modified Critical Strain Model, The American Society of Mechanical Engineers, Innovative Approaches to Irradiation Damage, and Fracture Analysis, 170: H00485. http://www.atc-ssm.com/pdf/PVP170-2.pdf.

5. Haggag, Fahmy M.; Wang, J.A.; Sokolov, M.A.; and Murty, K.L. 1987. Use of Portable/In-Situ SSM System to Measure Stress-Strain Behavior and Damage in Metallic Materials and Structures, Nontraditional Methods of Sensing Stress, Strain, and Damage in Materials and Structures, ASTM STP 1318. https://doi.org/10.1520/STP11894S.

6. Beghini, M.; Bertini, L.; Fontanari, V. 2006. Evaluation of the stress-strain curve of metallic materials by spherical indentation, International Journal of Solids and Structures, 43: 2441-2459. https://doi.org/10.1016/j.ijsolstr.2005.06.068.

7. Jose Luis Lanzagorta.; Antonio Martín-Meizoso. 2011. 3-Point Bending of Bars and Rods Made of Materials Obeying a Ramberg-Osgood Criterion, World Journal of Mechanics, 1: 71-77. https://doi.org/10.4236/wjm.2011.13010.

8. M. Szutkowska, 2005. Modified Indentation Methods for Fracture Toughness Determination of Alumina Ceramics, $13^{\text {th }}$ International conference on Achievements in Mechanical and Materials Engineering.

9. Wei, T.; Carr, D.G.; Budzakoska, E.; Payten, W.; Harrison, R.P.; Ripley, M.I. 2006. Assessment of The Fracture Toughness of 6061 Aluminium By The Small Punch Test and Finite Element Analysis, Institute of Materials Engineering Australasia Ltd, Materials Forum Volume 30. https://doi.org/10.1.1.606.8533.

10. Hiroaki Kurishita.; Takuya Yamamoto.; Takuya Nagasaka.; Arata Nishimura.; Takeo Muroga.; Shiro Jitsukawa, 2004. Fracture Toughness of JLF-1 by Miniaturized 3-Point Bend Specimens with 3.3-7.0 mm Thickness, Materials Transactions, 45-3: 936 - 941. https://doi.org/10.2320/matertrans.45.936.

11. Kamal Sharma.; Vivek Bhasin.; Ghosh, A.K. 2010. Property Estimation with Automated Ball Indentation Using Artificial Neural Network and Finite Element Simulation, Jordan Journal of Mechanical and industrial Engineering, 4: 503-506.

http://jjmie.hu.edu.jo/files/v4n4/Binder1.pdf.

\section{Joemax Agu, T. Christopher}

\section{FRACTURE TOUGHNESS EVALUATION OF AA3003 ALUMINUM ALLOY THROUGH ALTERNATIVE EXPERIMENTAL METHODS AND FINITE ELEMENT TECHNIQUE}

S u m m a r y

The fracture parameter most commonly used to analyze the integrity of engineering components is plane strain fracture toughness. The fracture toughness testing involved conventionally involves material cost and costly machine. However, alternative methods are used for in-situ applications which give reasonably good results. There is interest among researchers to use alternative methods for evaluating fracture toughness and to assess the material failure. This work aims at determining fracture toughness by ball indentation test and three point bend test and simulating those using ANSYS. The flow property of the selected material is also determined from the stress strain data by using ASTM E646-78. Excellent agreement was obtained from the experiments and empirical relations used for determination of fracture toughness by both methods.

Keywords: Finite Element Method, Fracture Toughness, Ball Indentation, 3point Bend Test, Material NonLinearity.

Received July 10, 2018

Accepted October 18, 2018 